九州大学学術情報リポジトリ

Kyushu University Institutional Repository

\title{
Synthesis of large area, homogeneous, single layer graphene films by annealing amorphous carbon on $\mathrm{Co}$ and $\mathrm{Ni}$
}

\section{Ago, Hiroki}

Institute for Materials Chemistry and Engineering, Kyushu University | Graduate School of Engineering Sciences, Kyushu University

$\mathrm{Hu}$, Baoshan

Institute for Materials Chemistry and Engineering, Kyushu University

Tsuji, Masaharu

Graduate School of Engineering Sciences, Kyushu University | Institute for Materials Chemistry and Engineering, Kyushu University

Orofeo, Carlo M.

Graduate School of Engineering Sciences, Kyushu University

http://hdl. handle. net/2324/25518

出版情報: Nano Research. 4 (6)，pp.531-540，2011-06-01. Tsinghua Press

バージョン：

権利関係: (C) Tsinghua University Press and Springer-Verlag Berlin Heidelberg 2011 
Synthesis of Large-Area, Homogeneous, Single Layer Graphene Films by Annealing Amorphous Carbon on $\mathrm{Co}$ and $\mathrm{Ni}$

Carlo M. Orofeo, Hiroki Ago*, Baoshan Hu, and Masaharu Tsuji

Kyushu University, Japan

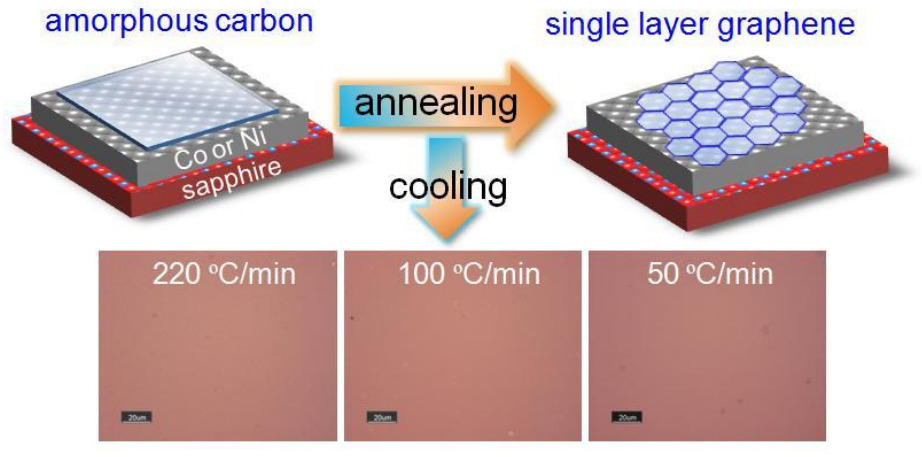

Synthesis of large area, homogeneous, single layer graphene films from amorphous carbon over $\mathrm{Co}$ or $\mathrm{Ni}$ is reported. The homogeneity of the graphene film is independent of cool-down rate. 


\title{
Synthesis of Large-Area, Homogeneous, Single Layer Graphene Films by Annealing Amorphous Carbon on Co and $\mathrm{Ni}$
}

\author{
Carlo M. Orofeo', Hiroki Ago ${ }^{1,2}(\bowtie)$, Baoshan $\mathrm{Hu}^{2}$, and Masaharu Tsuji ${ }^{1,2}$ \\ ${ }^{1}$ Graduate School of Engineering Sciences, Kyushu University, Kasuga, Fukuoka 816-8580, Japan \\ ${ }^{2}$ Institute for Materials Chemistry and Engineering, Kyushu University, Kasuga, Fukuoka 816-8580, Japan \\ Received: day month year / Revised: day month year / Accepted: day month year (automatically inserted by the publisher) \\ OThe Author(s) 2010. This article is published with open access at Springerlink.com
}

\begin{abstract}
Synthesis of large-area, homogenous, single layer graphene on cobalt (Co) and nickel (Ni) is reported. The process involves vacuum annealing of the sputtered amorphous carbon $(\mathrm{a}-\mathrm{C})$ deposited on $\mathrm{Co} /$ sapphire or $\mathrm{Ni} /$ sapphire substrate. The improved crystallinity of the used metal film assisted by sapphire substrate proves to be the key aspect to the quality of as-grown graphene film. Crystallinity of the Co and Ni metal films were improved by sputtering the metal at elevated temperature as verified by $\mathrm{x}$-ray diffraction (XRD). After sputtering of a-C and annealing, large-area, single layer graphene that occupies almost the entire area of the substrate is produced. With the method, $100 \mathrm{~mm}^{2}$-area single layer graphene can be synthesized and is limited only to the substrate and vacuum chamber size. The homogeneity of the graphene film is not dependent on the cooling rate as was expected with poly-crystalline metal films and conventional chemical vapor deposition (CVD) growth. Our facile method of producing single layer graphene on Co and Ni metal films has the potential for large-scale graphene-based applications.
\end{abstract}

\section{KEYWORDS}

Single layer graphene, amorphous carbon, epitaxial metal, annealing

Graphene, a quasi 2-dimensional (2D) material, has attracted much attention due to its great potential as an advanced material for future technologies [1]. In particular, single layer graphene's extraordinary mobility, easily in the order of $10000 \mathrm{~cm}^{2} \mathrm{~V}^{-1} \mathrm{~s}^{-1}$, has attracted interest in the application to nanoelectronics [2]. The earliest and simplest way to obtain graphene is by mechanical exfoliation of graphite using a scotch tape until single layer graphene is obtained. This method is only practical for laboratory experiments since the yield is very low and film sizes are relatively small [2]. Thus, it is important to find a method to synthesize large-area single layer graphene films suitable for large-scale production.

The formation of single layer graphene on

Address correspondence to ago@kyushu-u.ac.jp 
single-crystal transition metal substrates such as $\mathrm{Ni}(111)$ [3], $\mathrm{Ru}(0001)$ [4], and $\operatorname{Ir}(111)$ [5] have been demonstrated. However, due to the high cost of the substrates and limited scalability, the viability of a large scale production would be impractical to develop. Catalyctic chemical vapor deposition (CVD) on poly-crystalline $\mathrm{Ni}$ film deposited on $\mathrm{SiO}_{2} / \mathrm{Si}$ is also popular due to the simplicity of the process and scalability. One setback, however, is that the grown graphene is inhomogenous, which varies from single to multi-layers [6-12].

The segregation and precipitation of $\mathrm{C}$ atoms on poly-crystalline transition metals such as $\mathrm{Co}$ and $\mathrm{Ni}$ is a widely proposed mechanism for the formation of single layer and multi layer graphene using CVD [6-15]. Graphene is believed to precipitate from the dissolved $\mathrm{C}$ atoms in the metal during the cool-down step of the CVD process. For $\mathrm{Co}$ and $\mathrm{Ni}$, where solubility of carbon is relatively high $(\sim 1$ at. $\%$ at $1000{ }^{\circ} \mathrm{C}$ ), control of the morphology of the precipitated graphene film has been a challenging task. The goal is to develop a process to control the number of layer of graphene film and at the same time to make it homogenous and continuous in order to make it attractive for applications. As such, several groups have tried to control the thickness of graphene film by suppressing the amount of precipitated $C$ atoms that is strongly dependent on the cool down rate after CVD [6, 10-12]. However, the presence of grain boundaries, that acts as a preferential graphene nucleation sites in these poly-crytalline metal films, suggests an inherent inhomogeneity of the formed graphene films [10-12]. Another approach to control the amount of precipitated $C$ is by controlling the amount of carbon source $[13,14]$. To facilitate this, some groups used a solid carbon source to give a quantifiable conversion of the amount of $C$ to crystalline graphene [14]. However, the grown graphene still gives several layers of films perhaps due to the polycrystalline nature of the substrate used. Presently, only graphene films grown on $\mathrm{Cu}$ gives homogenous films due to the low carbon solubility on $\mathrm{Cu}$ and where the growth seems to be self-limited [16].

Here, we show that we can grow large-area, continuous, and single layer graphene films on thin film Co or Ni that was sputtered on c-plane (0001) sapphire substrate. Moreover, the homogeneity of the monolayer graphene film does not depend on the cool down rate. The key step is to improve the crystallinity of $\mathrm{Co}$ or $\mathrm{Ni}$ metal film used and to control the amount of $C$ source. Our method has the promise to further the research of graphene-based applications and will give more insights on the mechanism of graphene growth on highly crystalline substrates.

Shown in Figure 1 are the steps required for the growth and transfer of graphene films. We start the process by preparing the the metal substrate of Co or Ni. Recently, we have found a way to create highly crystalline metal film after sputtering on single crystalline $\mathrm{MgO}$ and c-plane sapphire $\left(\alpha-\mathrm{Al}_{2} \mathrm{O}_{3}\right)$ substrates [17,18]. Figure 1(a) illustrates the metal configuration. Briefly, the method involves sputtering of film on sapphire at elevated temperature $\left(500{ }^{\circ} \mathrm{C}\right)$ using radio-frequency (RF) magnetron sputtering (Shibaura Mechatoronics Corp., CFS-4ES) that was modified to include capability of substrate heating. In high-temperature sputtering, Co or $\mathrm{Ni}$ atoms can easily migrate due to the excess energy supplied from the heated substrate and form more ordered crystalline structure. The film thickness of the metal catalyst was set at $200 \mathrm{~nm}$. It was found out that after high temperature sputtering, only one peak of Co (fcc (111) or hcp (002)) can be seen through XRD reflecting the single crystalline nature of the deposited metal [18]. Shown in Fig. S-1 (Electronic Supplementary Material (ESM)) is the XRD profile of Co and Ni film after high temperature sputtering. The single peak at $\sim 44^{\circ}$ represents the fcc(111) or hcp (002) structure of Co or fcc(111) for Ni over c-plane sapphire. For comparison, room temperature $\left(27{ }^{\circ} \mathrm{C}\right)$ sputtering on $\mathrm{Co}$ and $\mathrm{Ni}$ over c-plane sapphire substrate was also performed. After XRD, several peaks on sputtered $\mathrm{Co}$ and $\mathrm{Ni}$ were observed suggesting poly-crystallinity of the metal films. Sputtering on heated $\mathrm{SiO}_{2}$ substrate also yield mutiple peaks suggesting the importance of base substrate for the epitaxial growth of crystalline metal films. After cooling down to room temperature, an amorphous carbon with thickness of $\sim 1.0 \mathrm{~nm}$ was then sputtered onto the highly crystalline metal film (Fig. 1(b)). The a-C thickness was optimized to give us a continuous graphene film with the minimum carbon supply (See discussion below). Sputtering of $\mathrm{a}-\mathrm{C}$ can be done successively after metal sputtering 
without breaking vacuum or it can be done with the metal exposed to air. However, in the case of the later, where the metal is exposed to the air, it was carefully safekeep to a vacuum storage to prevent oxidation of the metal before a-C sputtering. Runs involving a-C sputtering with and without breaking vacuum after metal sputtering resulted to graphene films with no significant differences in terms of homogeneity and Raman signatures. For comparison, the same method was done using $\mathrm{SiO}_{2} / \mathrm{Si}$ as the substrate during metal sputtering.

Next, the substrate was then heated to temperatures between $750{ }^{\circ} \mathrm{C}-800{ }^{\circ} \mathrm{C}$ under vacuum conditions. The annealing profile is illustrated in Fig. 1(c). Prior to annealing, the prepared substrate was loaded to a chamber (ULVAC Corp., MILA 3000) and was evacuated to reach a vacuum level of $\sim 3.0 \times$ $10^{-4} \mathrm{~Pa}$. The chamber was then heated to the desired temperature (Fig. 1(c), Stage 1) and after reaching the maximum temperature, it was held for 5 - 10 minutes (Fig. 1(c), Stage 2). At this stage, the deposited a-C is expected to diffuse into the metal. With the amount of a-C kept at minimal amount, it is expected at all a-C have diffused into the metal. The sample was then rapidly cooled down to room temperature with the maximum rates between between $200-290$ ${ }^{\circ} \mathrm{C} / \mathrm{min}$ depending on the annealing temperature. The maximum rate can be achieved by turning off the annealing chamber. The chamber can be programmed to give us a slower cool down rate as slow as $1^{\circ} \mathrm{C} / \mathrm{min}$ (Fig. 1(c), Stage 3). Previous studies involving poly-crystalline metal film showed the importance of cool down rate on the formation of single layer graphene. A slower cool down rate is expected to produce homogeneous single layer graphene films, while faster cooling gives multi-layer graphene flakes [10]. In our case, we found no discernables differences in our formed graphene with different cool down rate as will be discussed later in this paper. After annealing, graphene film is formed at the surface of the metals as depicted in Figure 1(d).

Optical analysis of the grown graphene can be best analyzed when the films are transferred on $\mathrm{SiO}_{2} / \mathrm{Si}$. To facilitate the transfer, a protective layer of poly-methyl methacrylate (PMMA, Aldrich Chemicals) was spin coated onto the graphene-metal substrate $[17,18]$. The PMMA/graphene can be detached from the metal by wet-etching using $\mathrm{FeCl}_{3}$ solution after which it can easily be transferred onto the $\mathrm{SiO}_{2} / \mathrm{Si}$ substrate (Fig. 1(e)). The PMMA layer can then be removed by soaking the substrate in acetone. We found out that graphene can best adhere onto the surface if it was heated after transfer at $100{ }^{\circ} \mathrm{C}$ for 10-20 mins prior to removal of PMMA. After removal of PMMA, the films retain its shape and continuity so that analyses of the resultant films after different process variations is possible. The graphene films were analyzed using optical microscope (NIKON ECLIPSE ME600 with CCD camera (NIKON, DXM1200), Raman that is equipped with Ar ion laser $(514.5 \mathrm{~nm})$ at spot size of $\sim 1 \mu \mathrm{m}$ (JASCO NRS-2100), atomic force microscope (AFM, Bruker Nanoscope IIIa), transmission electron microscope (TEM, HITACHI H-9500), and spectrophotometer (JASCO V-570) for transmittance measurements.

Shown in Fig. 2(a) is the optical image of the produced graphene on sputtered Co after transfer to $\mathrm{SiO}_{2} / \mathrm{Si}$. Even at relatively large area of $120 \mu \mathrm{m} \times 120$ $\mu \mathrm{m}$, the color is uniform. The uniformity in color suggested a homogenous film. The uniform color accounts to almost all of the total area of the metal film based from the optical images. However, we have found inhomogeneous films at some areas; we observed that the area that gave inhomogeneous film is the area with defects on metal after sputtering (See ESM, Fig. S-2(a,b) for images). We suspect that these areas gave preferential nucleation sites for thicker graphene. We used Raman microscopy, AFM, and TEM to evaluate the number of layer of the graphene film. Figure 2(b) displays the Raman spectra of the transferred film shown in Fig. 2(a). The spectra are from the spots marked with the corresponding colored circles in Fig. 2(a). All the Raman spectra show typical features of 1-2 layer graphene: (a) a $<1$ G/2D intensity ratio, (b) a symmetric 2D band centered at $\sim 2685 \mathrm{~cm}^{-1}$, and (c) a full width at half-maximum of 2D band from $30-40 \mathrm{~cm}^{-1}$. D band $\left(\sim 1360 \mathrm{~cm}^{-1}\right)$ and $\mathrm{D}^{\prime}$ band $\left(1625 \mathrm{~cm}^{-1}\right)$, which is associated with defects, is also prominent and is relatively high compared to other results that use CVD gases [7-9,16]. Although the origin of D and $\mathrm{D}^{\prime}$ bands for our process is still not fully understood, we have speculated that this is due to the non-CVD process and is frequently seen on similar studies using solid carbon sources $[13,14]$. Previous studies 
suggested that introduction of $\mathrm{H}_{2}$ gas prior to or during $C$ source introduction improves the quality of graphene films [11], similar to the effects observed with carbon nanotube synthesis [19]. Another possible reason is that our graphene contains wrinkle-induced defects or micro-cracks. Due to the rapid cool-down rate, wrinkles or micro-cracks could be induced from the difference in the thermal expansion of graphene and the underlying metal; similar to the proposed wrinkling formation on $\mathrm{Ni}$ $[11,13]$. The presence of residual amorphous carbon could also contribute to the higher D band intensity which is difficult to be isolated.

Further, the different Raman spectra taken from the different spots marked with corresponding colored circles showed similar spectrum. These indicate that the processed graphene is uniform. The uniformity can be quantitatively visualized by taking Raman maps. A portion of the film marked by the green area in Fig. 2(a) showed nearly uniform Raman maps for both $G$ band $(1580 \mathrm{~cm}-1)$ and 2D band $\left(2685 \mathrm{~cm}^{-1}\right)$ as shown in Fig. 2(c) and Fig. 2(d), respectively. Though the Raman features of $G / 2 D$ ratio $(\sim 0.7)$ at first glance suggested a bi-layer graphene, closer scrutiny on the $2 \mathrm{D}$ band showed a single Lorentzian fit and FWHM of $<40 \mathrm{~cm}^{-1}$ which suggested a monolayer graphene [20]. The relatively high $G / 2 D$ ratio could be due to the presence of dopants which are known to affect the $G$ and 2D intensities [21]. Therefore, for our process, Raman features alone cannot distinguish monolayer from bi-layer graphene. Further analysis using AFM as shown in Fig. 2(c) showed thickness between $0.8-1.2$ $\mathrm{nm}$ also suggesting layers of less than 3 [7]. This further supports that the formed graphene is either 1 to 2 layers. Finally, direct observation of the as-grown film by TEM confirms that the formed film is single layer graphene (Fig. 2(f)). As shown later, the light transmittance and optical microscope image analyses also support the growth of large-area, single-layer graphene. We were able to make single layer graphene in sizes limited only by the substrate and the annealing chamber size. Shown in Fig. 2(g) is the synthesized graphene film having an area of $>1$ $\mathrm{cm} \times 1 \mathrm{~cm}$ that was transferred on $\mathrm{SiO}_{2} / \mathrm{Si}$ which demonstrates the scalability of the method.

Previous studies pointed the importance of sputtering temperature and base substrate during metal sputtering to the quality of the resulting metal $[17,18]$. For example, sputtering of metal under ambient temperature $\left(27{ }^{\circ} \mathrm{C}\right)$ on c-plane sapphire, similar to the previous process but at lower temperature, resulted to poly-crystalline metal (Fig. $\mathrm{S}-1, \mathrm{ESM})$. The use of $\mathrm{SiO}_{2}$ substrate with Co metal that was sputtered at high temperature $\left(500{ }^{\circ} \mathrm{C}\right)$ resulted to a graphene film that is not homogeneous in color as shown in Fig. 3(a). The inhomogeneity in color indicates multiple film thickness $[7,9,18]$. This image is similar to the graphene flakes grown on poly-crystalline Ni [9-12]. The different Raman spectra presented in Fig. 3(b), as indicated in different corresponding colored circles, confirm graphene layers of different thicknesses. We note that $\mathrm{Ni}$ deposited on sapphire also gave single layer graphene, as shown in Figure S-2(c). The difference in the resulting graphene film by just changing the substrate is remarkable, and it gave us a template on the important parameter to control the number of graphene layers.

We grew graphene films on $\mathrm{Co}$ as a function of $\mathrm{a}-\mathrm{C}$ thickness and cool-down rate, with maximum temperature of $800{ }^{\circ} \mathrm{C}$. Graphene films can be grown up to temperatures of $950^{\circ} \mathrm{C}$, however we found that $750^{\circ} \mathrm{C}-800{ }^{\circ} \mathrm{C}$ is the optimum temperature that consistently gave us large-area and uniform graphene films. Shown in Fig. 4(a-c) are the films produced for different a-C thickness of 0.3, 1.0, $5.0 \mathrm{~nm}$, respectively. Annealing our substrate with an a-C thickness of $0.3 \mathrm{~nm}$, yield discontinuous graphene films. The graphene film does not fully cover the silicon oxide. We think that the carbon source is not enough to fully cover the whole surface area such that only selective areas were covered by graphene. The result give a logical scenario since assuming equal densities of as-deposited a-C and graphene, a $0.3 \mathrm{~nm}$ a-C thickness when converted to graphene is not enough to cover the whole surface. That conversion is evidenced by the discontinuous formation of graphene over the surface. At $1.0 \mathrm{~nm}$ thickness, the formed graphene covers the whole surface (Figure 4(b)). Increasing the thickness to 5 $\mathrm{nm}$, graphitic carbon as well as amorphous carbon were formed as detected from the Raman peaks ranging from $\sim 1250-1700 \mathrm{~cm}^{-1}$ (Fig. S-3, ESM). The result is not what we expect since a thicker graphene film is expected assuming a dissolution and 
segregation mechanism [14]. We think that our staging time might not be enough to fully dissolve the $\mathrm{a}-\mathrm{C}$, so we staged our samples 3 times longer. Indeed, after annealing at longer time, we got various thicknesses but not a uniform graphene film. Shown in Fig. 4(c) is the graphene after transfer onto $\mathrm{SiO}_{2} / \mathrm{Si}$ substrate. The Raman spectra representing the different thicknesses indicated in the colored circles is presented in Fig. 4(g).

The result suggested that there is an interplay in the thickness and anneal times to grow uniform graphene films. In the case of lower a-C thickness $(1.0 \mathrm{~nm})$, we can grow graphene even when the samples were cooled down right after reaching the annealing temperature ( 0 min staging time). This result suggests that the graphene growth on our highly crystalline substrate may not be all dissolution-precipitation but could also be direct crystallization during heating as observed by Saenger et al. [22]. However, without in-situ XRD which requires a special set-up, it is difficult to verify such process. For example, the Raman spectrum shown in Fig. S-3(b) does not distinguish the residual as-sputtered $\mathrm{a}-\mathrm{C}$ from the formed non-graphitic carbon after precipitation. Hence, a similar sputtering experiment was done using sputtered $\mathrm{Cu}$ metal film since $\mathrm{Cu}$ is known to produce graphene by direct crystallization on the substrate (adsorption) owing to the relatively low solubility rate of $\mathrm{C}$ on $\mathrm{Cu}$ [23]. However, we have not observed from Raman any graphene nor traces of a-C after annealing. In this case, the carbon atoms must have out-gassed to the system, dissolved in the metal, or remain on the surface that cannot be detected by our Raman system. Growth of graphene on $\mathrm{Cu}$ with the same method might require different experimental parameters which are not covered in this experiment.

Furthermore, we found that graphene growth on highly crystalline Co is independent of cool down rate; that is, slower cool down rate of $50{ }^{\circ} \mathrm{C} / \mathrm{min}$ yielded similar optical and Raman profiles to faster cool down rate of $220^{\circ} \mathrm{C} / \mathrm{min}$ (Fig. 4(d-f)). For such a big difference in cool-down rate $\left(170{ }^{\circ} \mathrm{C}\right)$, it appears that graphene formation is self-limited. Raman spectra taken randomly within the area showed similar features of 1-2 layer graphene for all the films at different cool down rate. A quick and reliable way to assess the number of layers of the uniform graphene films is by measuring the optical transmittance. From theory, single layer graphene attenuates light by $2.3 \%$ (97.7\% transmittance) at 550 $\mathrm{nm}$ while bilayer graphene should have transmittance of $95.4 \%$ [24]. Measurement of the transmittance was done after transferring the graphene film on transparent substrate like quartz and using a bare quartz as reference. Shown in the inset of Fig. 4(h) is the transferred graphene on a 10 $\mathrm{mm} \times 10 \mathrm{~mm}$ transparent quartz substrate. The diameter of our light source is $\sim 1.8 \mathrm{~mm}$; large enough to estimate the homogeneity of the films. Optical transmittance of the films produced using different cool down rate resulted to similar graphs (Fig. 4(h)). The graphs are assigned to single layer graphene which confirms our Raman measurements.

Another method to assess the graphene layer is to compare the contrast of the images of graphene on $\mathrm{SiO}_{2} / \mathrm{Si}$ against the image of the bare $\mathrm{SiO}_{2} / \mathrm{Si}$ substrate; the same method as applied by Reina et al. [10]. The optical contrasts of the images of the graphene grown at different cool down rate after transfer to $\mathrm{SiO}_{2} / \mathrm{Si}$ resulted to values associated with single layer graphene. Shown in Fig. S-4 (ESM) are the optical micrographs of the transferred films. Described also is the method for the identification of the number of layers.

For poly-crystalline $\mathrm{Co}$, such results would have been different and it is expected the dependence of the number of graphene layers on the cooling rate It has been reported for graphene grown on polycrystalline metal like $\mathrm{Ni}$ that the presence of grain boundaries promotes precipitation such that for any excess carbon, such sites acts as preferential nucleation sites for multi layer graphene. Therefore, the homogeneity of the graphene that were grown on Co/sapphire explains that the segregation mechanism on our highly crystalline substrates, with less grain boundaries, appears to be self-limited. This result is important because for metals having high carbon solubility, the precipitation process can be controlled to achieve simply by just improving the crystallinity of the underlying metal substrate.

In another case, direct crystallization of a-C to graphene may also be responsible for the independence of graphene films to different cooling rates. The precise mechanism will require additional experiments and will be the next logical step in this 
work.

We have investigated the transport properties of our grown graphene by making a graphene-based field effect transistor (FET) and measuring the sheet resistance using the van der Pauw method [25] after transfer to $\mathrm{SiO}_{2} / \mathrm{Si}$ substrate. Shown in Fig S-5(a) (ESM) is the transfer curve of the graphene film that was measured under ambient temperature and vacuum pressure of $\sim 1.0 \times 10^{-3} \mathrm{~Pa}$. From the curve, the carrier mobility was estimated to be $\sim 1050$ $\mathrm{cm}^{2} \mathrm{~V}^{-1} \mathrm{~s}^{-1}$. The Dirac point shifted to $\sim+48 \mathrm{~V}$ showing a p-type behavior which could be due to unintentional doping of our graphene by PMMA or the adsorption of $\mathrm{O}_{2}$ and/or $\mathrm{H}_{2} \mathrm{O}$ that suppressed the n-type conduction [26].

Our sheet resistances ranges from $16.7 \mathrm{k} \Omega / \square-$ $37.7 \mathrm{k} \Omega / \square$, an order of magnitude higher compared to the previous results of single layer graphene grown by conventional CVD on $\mathrm{Cu}$ [27] and $\mathrm{Ni}$ [28] but is comparable to FLG grown on $\mathrm{Ni}$ [9] and earlier results of CVD grown graphene on $\mathrm{Cu}$ [29]. The increase in resistance can be attributed to several factors: (1) the transfer process on $\mathrm{SiO}_{2} / \mathrm{Si}$ produced cracks or tear that increases the resistance (see ESM Fig. S-5(b)), (2) the PMMA may have contributed to the sheet resistance of the graphene film [30], (3) the contribution of the contact resistance of the electrode and graphene, and (4) the relatively high-intrinsic defects (as shown from $\mathrm{D}$ and $\mathrm{D}^{\prime}$ band intensities) lead to a dramatic increase in sheet resistance. For all of the cases, a systematic experiment is currently being performed and the results will be published elsewhere.

In conclusion, we have demonstrated that large-area, homogenous, single layer graphene films can be grown on metals with high $\mathrm{C}$ solubility such as $\mathrm{Co}$ or $\mathrm{Ni}$ by simply annealing the amorphous carbon. The graphene film covers the whole area of the metal films. This can be done by improving the crystallinity of the metal film by sputtering at high temperature on appropriate substrates and using limited carbon source. Remarkably, the homogeneity of the film is independent of the cool down rate in contrast to polycrystalline metals where the graphene films vary from few layers to graphite. We think that the presence of very few grain boundaries on our crystalline substrate suppresses the precipitation of carbon such that it appears to be self-limited or the direct crystallization of our limited a-C can also play a role.

\section{Acknowledgements}

We would like to thank PRESTO, Japan Science and Technology (JST), Grant-in-Aid for Scientific Research from MEXT, and JSPS Funding Program for World-Leading Innovative R\&D on Science and Technology (Development of Core Technologies for Green Nanoelectronics) for the support. We acknowledge Prof. Hiroshi Nakashima and Keisuke Yamamoto for helping us with the sheet resistance measurements. CMO acknowledges the support from Global Center of Excellence (GCOE) funding.

Electronic Supplementary Material: XRD measurement of the metals, optical photos of the graphene films, details of the number of layer determination by optical contrast, and photos of graphene after transfer for sheet resistance measurement are available in the online version of this article at

http://dx.doi.org/10.1007/10.1007/s12274_-*******_* and are accessible free of charge.

Open Access: This article is distributed under the terms of the Creative Commons Attribution Noncommercial License which permits any noncommercial use, distribution, and reproduction in any medium, provided the original author(s) and source are credited.

\section{References}

[1] Geim, A. K.; Novoselov, K. S. The rise of graphene. Nat. Mater. 2007, 6, 183-191.

[2] Novoselov, K. S.; Geim, A. K.; Morozov, S. V.; Jiang, D.; Zhang, Y.; Dubonos, S. V.; Grigorieva, I. V.; Firsov, A. A. Electric field effect in atomically thin carbon films. Science 2004, 306, 666-669.

[3] Usachov, D.; Dobrotvorskii, A. M.; Varykhalov, A.; Rader, O.; Gudat, W.; Shikin, A. M.; Adamchuk, V. K. Experimental and theoretical study of the morphology of commensurate and incommensurate graphene layers on $\mathrm{Ni}$ single-crystal surfaces. Phys. Rev. B 2008, 78, 85403.

[4] Sutter, P. W.; Flege, J.-I.; Sutter, E. A. Epitaxial graphene on ruthenium. Nat. Mater. 2008, 7, 406-411. 
[5] N'Diaye, A. T.; Bleikamp, S.; Feibelman, P. J.; Michely, T. Two-dimensional Ir cluster lattice on a graphene Moire' on Ir(111), Phys. Rev. Lett. 2006, 97, 215501.

[6] Yu, Q. K.; Lian, J.; Siriponglert, S.; Li, H.; Chen, Y. P.; Pei, S. - S. Graphene segregated on Ni surfaces and transferred to insulators. Appl. Phys. Lett. 2008, 93, 113103.

[7] Reina, A.; Jia, X. T.; Ho, J.; Nezich, D.; Son, H. B.; Bulovic, V.; Dresselhaus, M. S.; Kong, J. Large area, few-layer graphene films on arbitrary substrates by chemical vapor deposition. Nano Lett. 2009, 9, 30-35.

[8] Kim, K. S.; Zhao, Y.; Jang, H.; Lee, S. Y.; Kim, J. M.; Kim, K.S.; Ahn, J. -H.; Kim, P.; Choi, J. -Y.; Hong, B. H. Large scale pattern growth of graphene films for stretchable transparent electrodes. Nature 2009, 457, 706-710.

[9] De Arco, L. G.; Yi, Z.; Kumar, A.; Chongwu, Z. Synthesis, transfer, and devices of single- and few-layer graphene by chemical vapor deposition. IEEE Trans. Nanotechnol. 2009 , $8,135-138$.

[10] Reina, A.; Theile, S.; Xiaoting, J.; Bhaviripudi, D.; Dresselhaus, M. S.; Schaefer, J. A.; Kong, J. Growth of large-area, single- and bi-layer graphene by controlled carbon precipitation on polycrystalline $\mathrm{Ni}$ surfaces. Nano Res. 2009, 2, 509-516.

[11] Chae, S. J.; Günes, F.; Kim, K. K.; Kim, E. S.; Han, G. H.; Kim, S. M.; Shin, H. -J.; Yoon, S. -M.; Choi, J. -Y.; Park, M. H.; Yang, C. W.; Pribat, D.; Lee, Y. H. Synthesis of large-area graphene layers on poly-nickel substrate by chemical vapor deposition: wrinkle formation. Adv. Mater. 2009, 21, 1-6.

[12] Liu, W.; Chung, C. -H.; Miao, C. -Q.; Wang, Y.-J.; Li, B. -Y.; Ruan, L. -Y.; Patel, K.; Park, Y.-L.; Woo, J.; Xie, Y. -H. Chemical vapor deposition of large area few layer graphene on $\mathrm{Si}$ catalyzed with nickel films. Thin Solid Films 2010, 518, 128-132.

[13] Pollard, A. J.; Nair, R. R.; Sabki, S. N.; Staddon, C. R.; Perdigao, L. M. A.; Hsu, C. H.; Garfitt, J. M.; Gangopadhyay, S.; Gleeson, H. F.; Geim, A. K.; Beton, P. $\mathrm{H}$. Formation of monolayer graphene by annealing sacrificial nickel thin films. J. Phys. Chem. C 2009, 113, 16565-16567.

[14] Zheng, M.; Takei, K.; Hsia, B.; Fang, H.; Zhang, X.; Ferralis, N.; Ko, H.; Chueh, Y.-L.; Zhang, Y.; Maboudian, R.; Javey, A. Metal-catalyzed crystallization of amorphous carbon to graphene. Appl. Phys. Lett. 2010, 96, 063110.

[15] Hofrichter, J.; Szafranek, B. N.; Otto, M.; Echtermeyer, T. J.; Baus, M.; Majerus, A.; Geringer, V.; Ramsteiner, M.; Kurz, H. Synthesis of graphene on silicon dioxide by a solid carbon source. Nano Lett. 2010, 10, 36-42.

[16] Li, X.; Cai, W.; An, J.; Kim, S.; Nah, J.; Yang, D.; Piner, R.; Velamakanni, A.; Jung, I.; Tutuc, E.; Banerjee, S. K.; Colombo, L.; Ruoff, R. S. Large-area synthesis of high-quality and uniform graphene films on copper foils. Science 2009, 324, 1312-1314.

[17] Ago, H.; Tanaka, I.; Orofeo, C. M.; Tsuji, M.; Ikeda, K. Patterned growth of graphene over epitaxial catalyst. Small 2010, 6, 1226-1233.
[18] Ago, H.; Ito, Y.; Mizuta, N.; Yoshida, K.; Hu, B.; Tsuji, M.; Mizuno, S. Epitaxial CVD growth of single-layer graphene over Co film crystallized on sapphire. ACS Nano 2010, 4, 7407-7414.

[19] Zhang, G.; Mann, D.; Zhang, L.; Javey, A.; Li, Y.; Yenilmez, E.; Wang, Q.; McVittie, J. P.; Nishi, Y.; Gibbons, J.; Dai, H. Ultra-high-yield growth of vertical single-walled carbon nanotubes: hidden roles of hydrogen and oxygen. Proc. Natl. Acad. Sci. 2005, 102, 16141-16145.

[20] Ferrari, A. C.; Meyer, J. C.; Scardaci, V.; Casiraghi, C.; Lazzeri, M.; Mauri, F.; Piscanec, S.; Jian, D.; Novoselov, K. S.; Roth, S.; Geim, A. K. Raman spectrum of graphene and graphene Layers. Phys. Rev. Lett. 2006, 97, 187401.

[21] Das, A.; Pisana, S.; Chakraborty, B.; Piscanec, S.; Saha, S. K.; Waghmare, U. V.; Novoselov, K. S.; Krishnamurthy, H. R.; Geim, A. K.; Ferrari, A. C.; Sood, A. K. Monitoring dopants by Raman scattering in an electrochemically top-gated graphene transistor. Nat. Nanotechnol. 2008, 3, 210-215.

[22] Saenger, K. L.; Tsang, J. C.; Bol, A. A.; Chu, J. O.; Grill, A.; Lavoie, C. In situ x-ray diffraction study of graphitic carbon formed during heating and cooling of amorphous-C/Ni bilayers. Appl. Phys. Lett. 2010, 96, 153105.

[23] Li, X.; Cai, W.; Colombo, L.; Ruoff, R. Evolution of graphene growth on $\mathrm{Ni}$ and $\mathrm{Cu}$ by carbon isotope labeling. Nano Lett. 2009, 9, 4268-4272.

[24] Nair, R. R.; Blake, P.; Grigorenko, A. N.; Novoselov, K. S.; Booth, T. J.; Stauber, T.; Peres, N. M. R.; Geim, A. K. Fine structure constant defines visual transparency of graphene. Science 2008, 320, 1308.

[25] Van der Pauw, L. J. A method of measuring the resistivity and hall coefficient on lamellae of arbitrary shape. Philips Tech. Rev. 1958, 20, 220-224.

[26] Lafkioti, M.; Krauss, B.; Lohmann, T.; Zschieschang, U.; Klauk, H.; v. Klitzing, K.; Smet, J. Graphene on a hydrophobic substrate: doping reduction and hysteresis suppression under ambient conditions. Nano Lett. 2010, 10, 1149-1153.

[27] Li, X.; Zhu, Y.; Cai, W.; Borysiak, M.; Han, B.; Chen, D.; Piner, R.; Colombo, L.; Ruoff, R. Transfer of large-area graphene films for high-performance transparent conductive electrodes. Nano Lett. 2009, 9, 4359-4363.

[28] Kim, K. S.; Zhao, Y.; Jang, H.; Lee, S. Y.; Kim, J. M.; Kim, K. S.; Ahn, J.-H.; Kim, P.; Choi, J.-Y.; Hong, B. H. Large-scale pattern growth of graphene films for stretchable transparent electrodes. Nature 2009, 457, 706-710.

[29] Li, X.; Cai, W.; Jung, I.; An, J.; Yang, D.; Velamakanni, A.; Piner, R.; Colombo, L.; Ruoff, R. Synthesis, characterization, and properties of large-area graphene films. ECS Transactions, 2009, 19, 41-52.

[30] Lohmann, T.; von Klitzing, K.; Smet, J. H. Four-terminal magneto-transport in graphene $\mathrm{p}-\mathrm{n}$ junctions created by spatially selective doping. Nano Lett. 2009, 9, 1973-1979. 
(a)

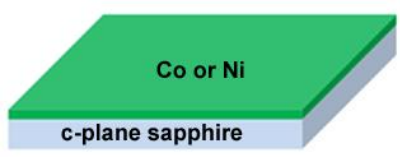

(d)

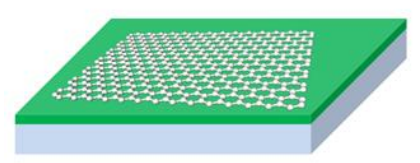

(b)

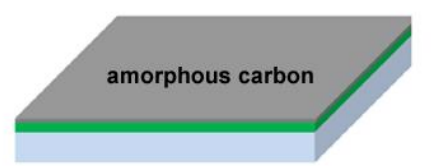

(e)

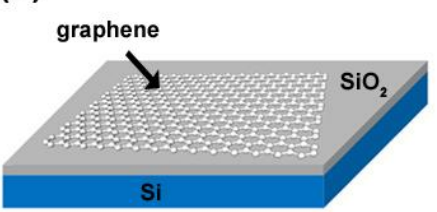

(c)

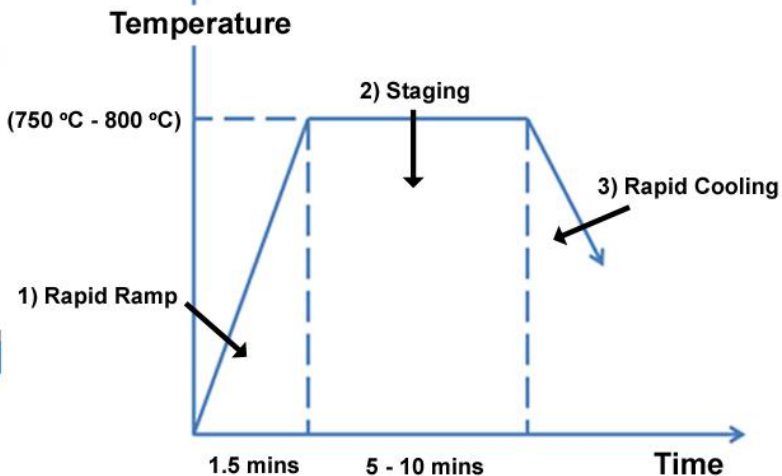

Figure 1 Schematic of the graphene growth process: (a) A thin metal film ( $200 \mathrm{~nm})$ of Co or Ni is sputtered on c-plane sapphire substrate at high temperature $\left(\sim 500{ }^{\circ} \mathrm{C}\right)$ to produce crystalline metal substrate. (b) After cool down to room temperature, a thin amorphous carbon $(\mathrm{a}-\mathrm{C})$ was sputtered on top of the metal film. The substrate was then annealed under vacuum pressure of $\sim 3.0 \mathrm{x}$ $10^{-4} \mathrm{~Pa}$ using the process steps in (c); 1) The a-C/metal/sapphire was rapidly heated to annealing temperature $\left(750{ }^{\circ} \mathrm{C}-800{ }^{\circ} \mathrm{C}\right)$ for 1.5 minutes. 2) The substrate was then made to stay at the peak temperature for $5-10$ mins. At this point, the a-C is expected to dissolve into the metal film. After staging, the substrate was then made to cool down at rates that can be controlled by the annealing chamber. (d) After annealing, graphene is formed on the surface of the metal, followed by transferring onto $\mathrm{SiO}_{2} / \mathrm{Si}$ (e) for further analyses 

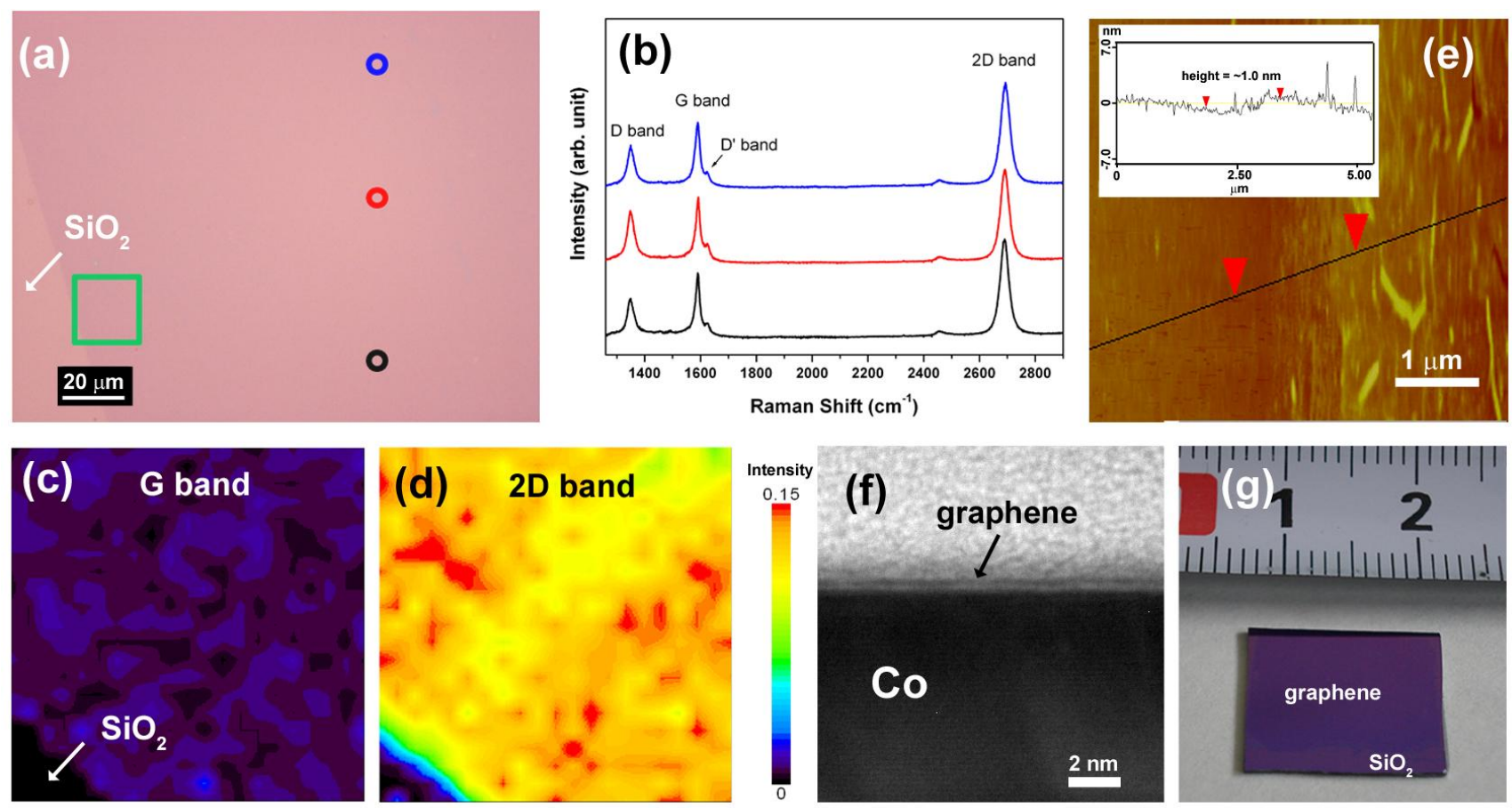

Figure 2. Characterization of the transferred graphene film. (a) Optical microscope image of the graphene film that was grown on Co film and transferred onto target $\mathrm{SiO}_{2}(300 \mathrm{~nm}) / \mathrm{Si}$ substrate. The $\mathrm{SiO}_{2}$ substrate and graphene are indicated. (b) Representative Raman spectra from the marked spots with corresponding colored circles in (a) showing nearly the same spectrum profile indicating the homogeneity of the transferred film. (c,d) A $20 \mu \mathrm{m} \times 20 \mu \mathrm{m}$ Raman intensity maps of the G band $\left(1580 \mathrm{~cm}^{-1}\right)$ and $2 \mathrm{D}$ band $\left(2685 \mathrm{~cm}^{-1}\right)$, respectively, of the green square area indicated in (a). Indicated in the lower left border is the $\mathrm{SiO}_{2}$. The scale bar to the right is for both $\mathrm{G}$ and $2 \mathrm{D}$ band. (e) AFM image of the transferred graphene taken at the edge of the $\mathrm{SiO}_{2}$ to measure the graphene height. (f) TEM image of the as-grown graphene on Co confirming the single layer graphene. (g) Large-area graphene film (at least 1 $\mathrm{cm} \times 1 \mathrm{~cm}$ ) grown on $\mathrm{Co} /$ sapphire substrate after transfer onto $\mathrm{SiO}_{2} / \mathrm{Si}$ substrate. Graduation of the scale is $1 \mathrm{~mm}$ 

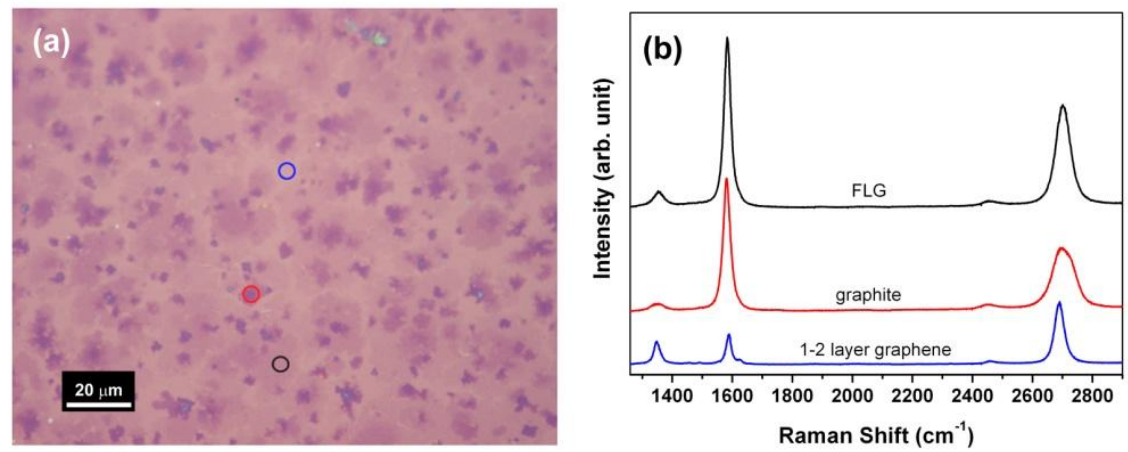

Figure 3 (a) Optical microscope image of the graphene film that was grown on $\mathrm{Co} / \mathrm{SiO}_{2} / \mathrm{Si}$ after transferring onto $\mathrm{SiO}_{2} / \mathrm{Si}$ substrate. (b) Raman spectra from the marked spots with corresponding colored circles in (a) showing different film thicknesses (see text for details) 

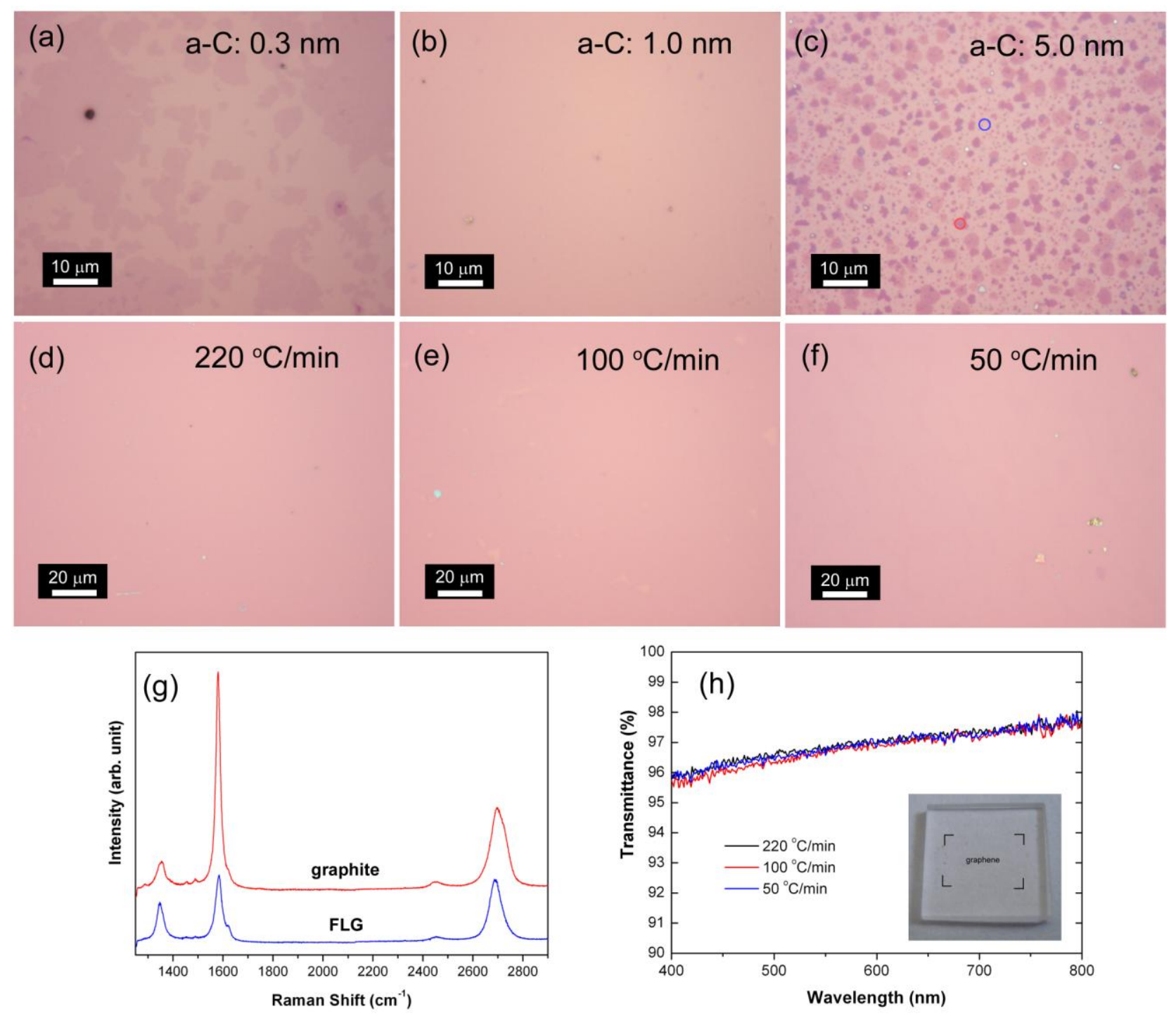

Figure 4 Dependence of a-C thickness and cooling rate on the formation of graphene films. (a-c) Optical microscope images of the transferred graphene grown at different a-C thickness. (d-f) Optical microscope images of the transferred graphene grown at different cool-down rate as indicated (a-C thickness is $1.0 \mathrm{~nm}$ ). Even at different cool down rate, continuous graphene films are produced with no discernable difference in terms of homogeneity of the film. (g) Raman spectra of the indicated circles in (c) indicating the different graphene thicknesses. (h) Transmittance of graphene films produced at different cool down rate as indicated. All films showed transmittance characteristics of single-layer graphene film. Inset is the transferred graphene on a $10 \mathrm{~mm} \times 10 \mathrm{~mm}$ quartz substrate 


\title{
Electronic Supplementary Material
}

\section{Synthesis of Large-Area, Homogeneous, Single Layer Graphene by Annealing Amorphous Carbon on Co and Ni}

\author{
Carlo M. Orofeo ${ }^{\perp}$, Hiroki Ago ${ }^{\perp,\llcorner}(\bowtie)$, and Baoshan $\mathrm{Hu}^{2}$, Masaharu Tsuji ${ }^{1,2}$ \\ ${ }^{1}$ Graduate School of Engineering Sciences, Kyushu University, Kasuga, Fukuoka 816-8580, Japan \\ ${ }^{2}$ Institute for Materials Chemistry and Engineering, Kyushu University, Kasuga, Fukuoka 816-8580, Japan
}

Supporting information to DOI 10.1007/s12274-****_****_* (automatically inserted by the publisher) 

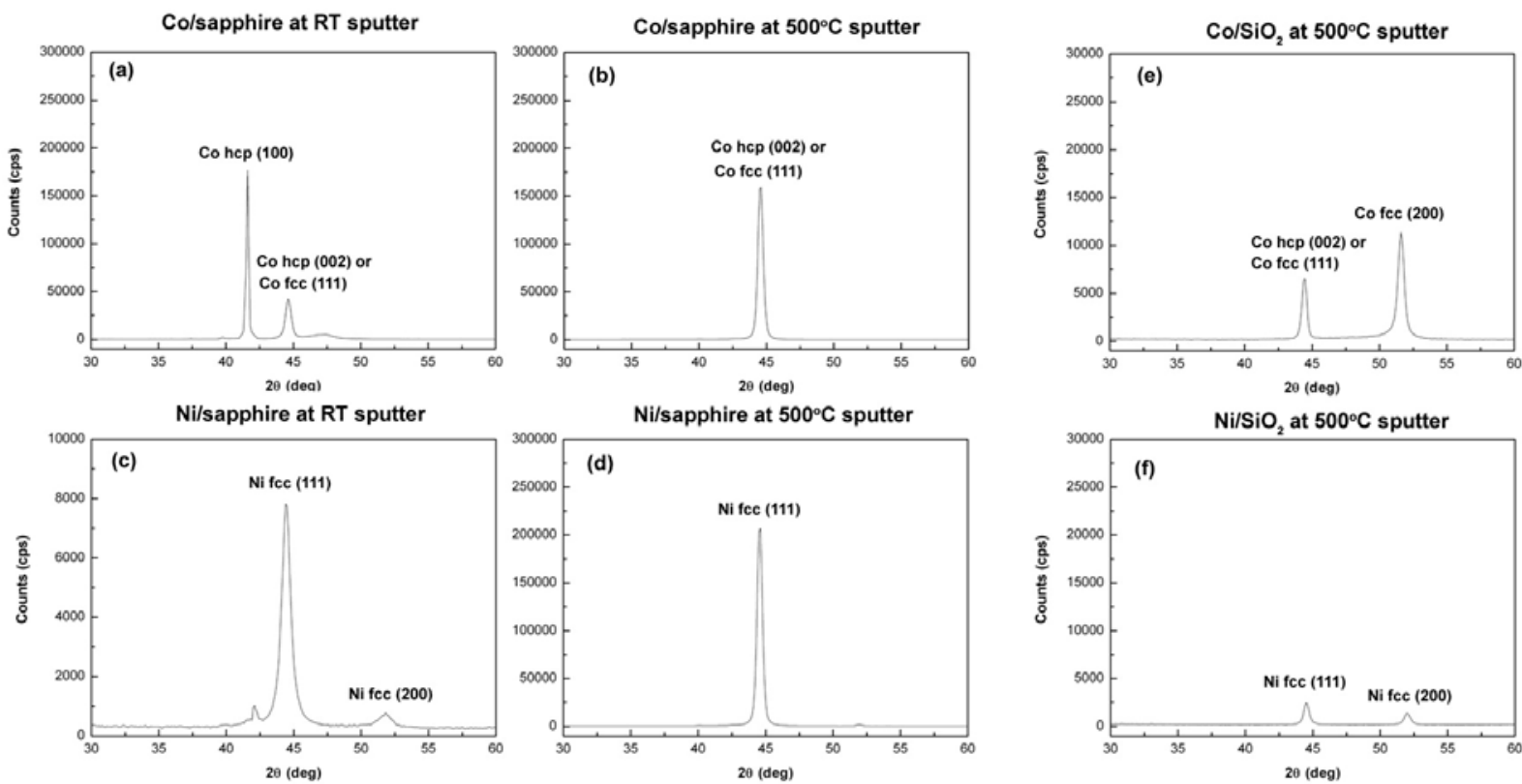

Figure S-1 XRD Profiles of Co and Ni films after sputtering at different conditions. XRD profile of Co sputtered on sapphire substrate at (a) room temperature (RT) showing 2 peaks, which signifies a poly-crystal substrate, and (b) $500{ }^{\circ} \mathrm{C}$ showing a single peak, which signifies a single crystal substrate. XRD profile of Ni sputtered on sapphire substrate at (c) room temperature (RT) showing 2 peaks, which signifies a poly-crystal substrate, and (d) $500{ }^{\circ} \mathrm{C}$ showing a single peak, which signifies a single crystal substrate. (e,f) $\mathrm{Co}$ and $\mathrm{Ni}$, respectively, sputtered on $\mathrm{SiO}_{2} / \mathrm{Si}$ substrate at $500{ }^{\circ} \mathrm{C}$ with both substrates showing multiple peaks signifying poly-crystallinity of the substrates 

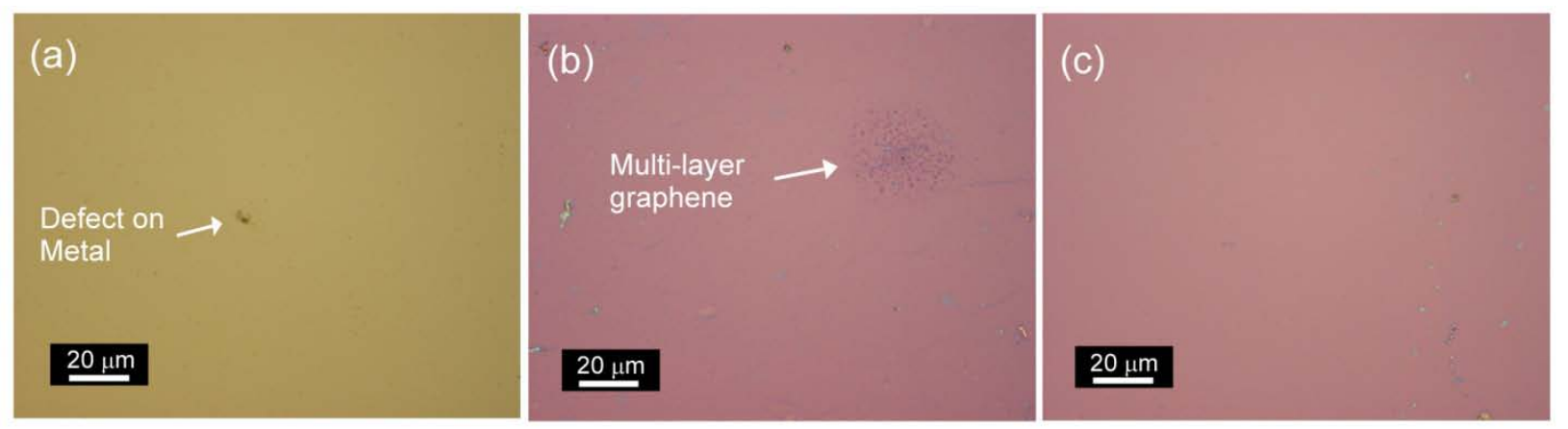

Figure S-2 (a) Optical microscope image of Co on sapphire substrate after annealing at $800{ }^{\circ} \mathrm{C}$. A defect is indicated that can be a nucleation site for multi-layer graphene. (b) Optical microscope image of the graphene film that was grown on Co/sapphire after transferring onto $\mathrm{SiO}_{2}(300 \mathrm{~nm}) / \mathrm{Si}$ substrate. Indicated is an area with multi-layer graphene where a defect was previously found. (c) Optical microscope image of the graphene film that was grown on $\mathrm{Ni} / \mathrm{sapphire}$ after transferring onto $\mathrm{SiO}_{2}(300 \mathrm{~nm}) / \mathrm{Si}$ substrate 

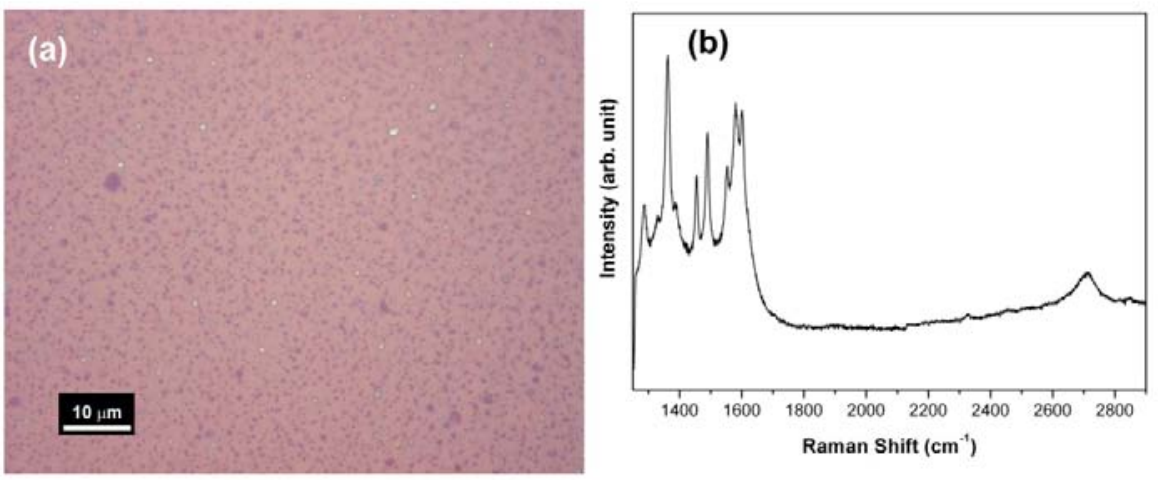

Figure S-3 (a) Optical microscope image of the graphene film that was grown on Co/sapphire with $5 \mathrm{~nm}$ a-C thickness after transferring onto $\mathrm{SiO}_{2}(300 \mathrm{~nm}) / \mathrm{Si}$ substrate. (b) Raman data from (a) showed multiple peaks from $1250-1700 \mathrm{~cm}^{-1}$ which indicates some partial formation of graphitic carbon and amorphous carbon 

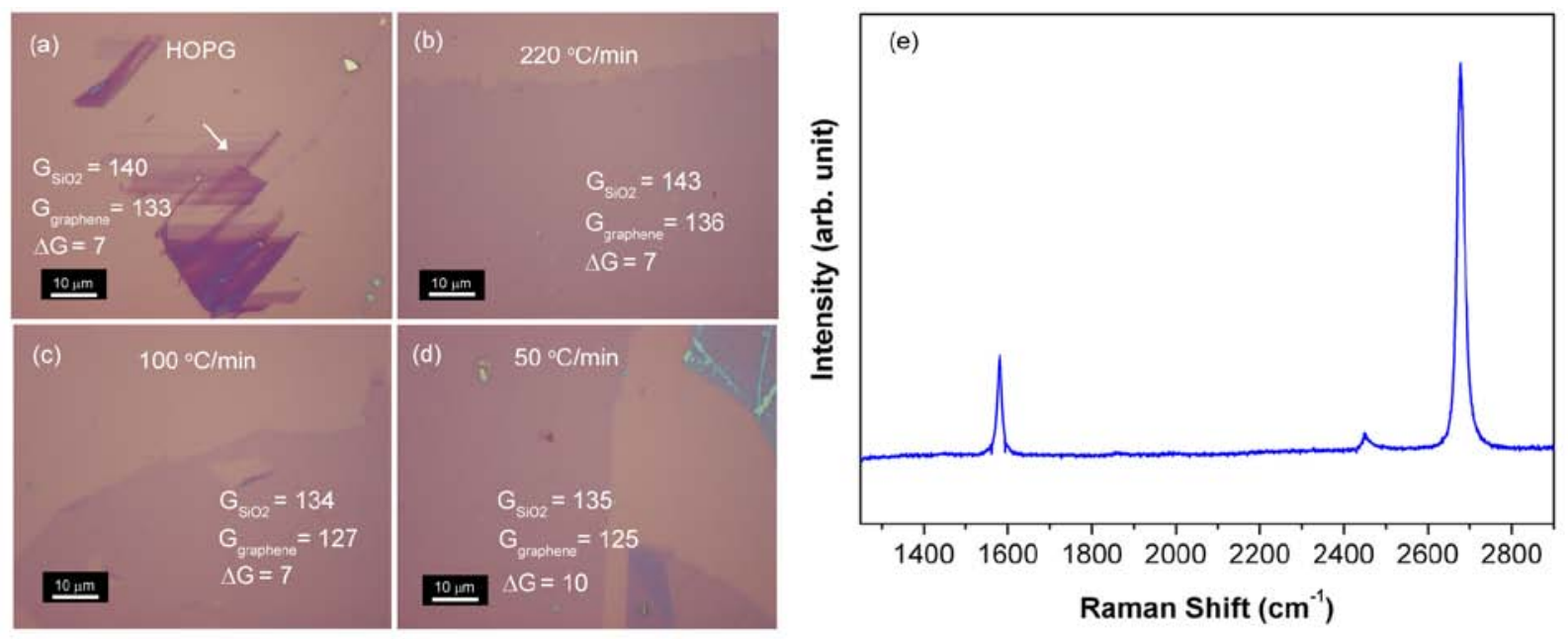

Figure S-4 Optical microscope image exfoliated graphene from HOPG (a). Optical microscope images of graphene films grown on Co/sapphire with different cool down rate of $220{ }^{\circ} \mathrm{C} / \mathrm{min}$ (b), $100{ }^{\circ} \mathrm{C} / \mathrm{min}$ (c) and $50{ }^{\circ} \mathrm{C} / \mathrm{min}$ (d). The images were taken at the same magnification (100×) and light settings. (e) Raman spectrum of the portion indicated by an arrow in (a), which indicates that the area is single layer

\section{Determination of the number of layer using optical images}

In order to determine the number of graphene layer from the optical images, the same method employed by Reina et al. [1] was used. This was accomplished by taking the difference of the green components (denoted as $\Delta \mathrm{G}$ ) of the stacked graphene/ $\mathrm{SiO}_{2}$ and bare $\mathrm{SiO}_{2}$ and comparing it to the predicted difference of these values derived from computation. Prior to comparison, a calibration on the difference of green component, G, was done on exfoliated graphene from HOPG. Shown in Fig. S-4(a) is the exfoliated graphene on $\mathrm{SiO}_{2}$. The area indicated in the arrow is single layer graphene based from the Raman spectrum shown in Fig. S-4(e). The green component of the bare $\mathrm{SiO}_{2}$ (denoted as $\mathrm{GsiO}_{2}$ ) taken within the proximity of the graphene on $\mathrm{SiO}_{2}$ (denoted as Ggraphen) was then subtracted from the green component of the graphene $/ \mathrm{SiO}_{2}$ stack. The difference, $\Delta \mathrm{G}$, was then compared to the predicted difference derived from modeling [1]. The value of $\Delta G=7$ shown in Fig. S-3(a) agrees well with the value for single layer graphene. The Ggraphene was taken at the location of the arrow. Images of graphene grown at different cool down rate (Fig. S-4(b-d)) was then taken at the same magnification and light settings with HOPG. The same procedure was done for comparison of $\Delta \mathrm{G}$. Comparison of all values to the predicted $\Delta \mathrm{G}$ value indicates that the all the grown graphene is single layer.

\section{Reference:}

[1] Reina, A.; Theile, S.; Xiaoting, J.; Bhaviripudi, D.; Dresselhaus, M. S.; Schaefer, J. A.; Kong, J. Growth of large-area, singleand bi-layer graphene by controlled carbon precipitation on polycrystalline Ni surfaces. Nano Res. 2009, 2, 509-516. 

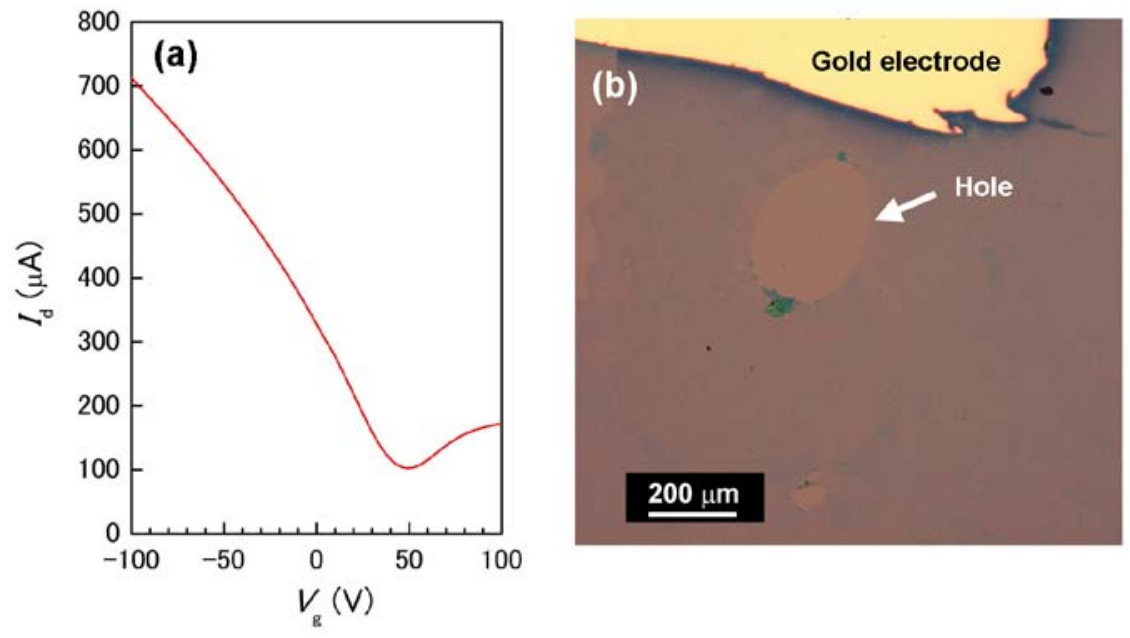

Figure S-5 (a) Transfer characteristics of the graphene film that was transferred onto a $\mathrm{SiO}_{2} / \mathrm{Si}$ substrate $\left(\mathrm{V}_{d}=0.1 \mathrm{~V}\right.$, channel length and width are $10 \mu \mathrm{m}$ and $50 \mu \mathrm{m}$, respectively). (b) Optical microscope image of the graphene film after transfer to SiO$/ 2 \mathrm{Si}$ for sheet resistance measurement showing defects such as the indicated hole. Gold with thickness of $\sim 50 \mathrm{~nm}$ was used as electrode. 